\title{
Geometry Parametrization and Aerodynamic Characteristics of Axisymmetric Afterbodies
}

\author{
G. Zuccolo' ${ }^{1}$ D. MacManus ${ }^{2}$ and I. Goulos ${ }^{3}$ \\ Cranfield University, Cranfield, Bedfordshire, MK43 OAL, United Kingdom
}

P. Martin 4

Defence Science and Technology Laboratory, Portsdown West, Fareham, PO17 6AD, United Kingdom

\begin{abstract}
A key aspect of the preliminary design process for a new generation combat aircraft is the prediction of afterbody aerodynamic drag. Current prediction methods for preliminary design are constrained in terms of number of independent geometric degrees of freedom that can be studied due to the classic circular arc or conical afterbody geometry parametrization. In addition, the amount of data available for the construction of the reliable performance correlations is too sparse. This paper presents a methodology for the generation of aerodynamic performance maps for transonic axisymmetric afterbody and exhaust systems. It uses a novel parametric geometry definition along with a compressible flow solver to conduct an extensive design space exploration. The proposed geometry parametrization is based on the Class Shape Transformation method and it enables the assessment of the aerodynamic performance of a wider range of afterbodies at the expense of one additional geometric degree of freedom. Relative to the conventional approach, this enables the exploration of a wider design space and the construction of more complete aerodynamic performance maps. This research quantifies the impact of a number of geometric degrees of freedom on the aerodynamic performance of transonic afterbody and exhaust systems at different operating conditions.
\end{abstract}

\section{Nomenclature}

Roman symbols:

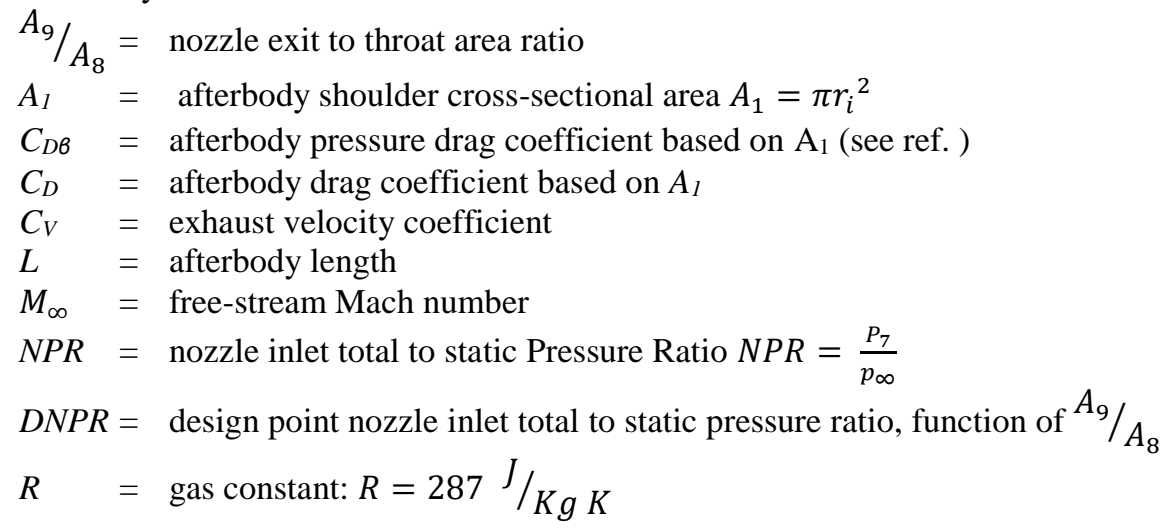

\footnotetext{
${ }^{1}$ PhD Candidate, Centre for Propulsion Engineering, g.zuccolo@cranfield.ac.uk.

${ }^{2}$ Head of Gas Turbine Technology Group, Centre for Propulsion Engineering, D.G.Macmanus@ cranfield.ac.uk.

${ }^{3}$ Lecturer in Propulsion Integration, Centre for Propulsion Engineering, i.goulos@cranfield.ac.uk.

${ }^{4}$ Principal Scientist, Defence Science and Technology Laboratory.
} 


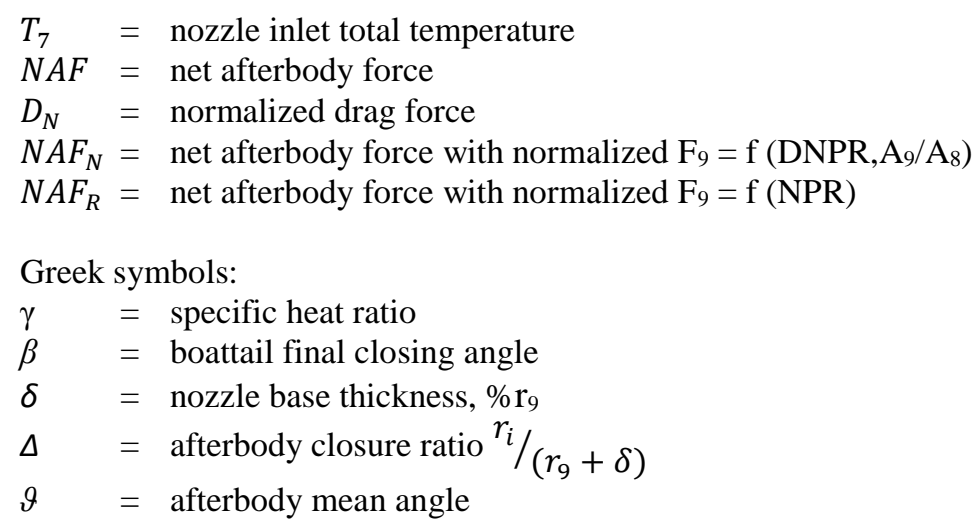

\section{II.Introduction}

Some new generation fighter aircraft are expected to be multi-role vehicles designed to perform a variety of missions. The required flexibility makes the design process more challenging and different requirements must be taken into account over a wide range of flight Mach numbers and engine power settings. These requirements may include high manoeuvrability, low infrared signature, thrust vectoring, variable area nozzle and low radar signature as well as extended range [1]. To comply with these performance demands the integration of the propulsion system within the aircraft is a key consideration. Intakes and afterbody-nozzle systems can include moving parts to efficiently accommodate different power settings and flight speeds. In addition, due to weight, balance and internal packaging requirements, fighter-type aircraft tend to incorporate short, steep afterbodies which may be prone to external flow separation [2].

Although an aircraft has many sources of drag, not all the components contribute in the same manner. For instance, in some vehicles the afterbody can account for up to $30 \%$ of the zero-lift drag [3]. Consequently it is important to understand the afterbody drag sensitivity to geometric features, engine power settings and aircraft flight conditions. Past studies ([2], [4], [5]) have experimentally addressed the effect of $M_{\infty}$, NPR and afterbody mean angle ( $)$ on drag for simple geometry parametrizations such as circular arc and conical afterbodies. These parametrizations are defined by a second order equation and a first order equation respectively. This over restricts the number of geometric Degrees of Freedom (DoF) that can be explored independently within a Design Space Exploration (DSE) to afterbody length $(\mathrm{L})$ and closure ratio $(\Delta)$ and leads to sparse data that is difficult to use within a preliminary design process [6].

This study proposes a new methodology for afterbody geometry parametrization based on the Class Shape Transformation (CST) method [7], [8]. This increases the number of independent geometric DoF to three: L, $\vartheta$ and $\beta$. The performance maps are generated by means of steady compressible Computational Fluid Dynamics (CFD) simulations. Moreover, this work quantitatively assesses the benefits of the additional DoF $(\beta)$ within the context of a preliminary design process.

\section{III.Background}

Conventional afterbody and nozzle systems for combat aircraft in dry cruise power settings are, in many cases, parametrized with a circular arc geometry [4]. This parametrization gives a simple analytical geometry representation method and it generates shapes with a reasonable aerodynamic drag performance and reduced length [2], [4]. A circular arc afterbody is defined with three independent geometrical constraints. These are the afterbody length (L), radial offset of the end points $\left(r_{i}-r_{9}\right)$ and geometry slope at $P_{1}=\left[0, r_{i}\right]$ (Fig. 1). This uniquely defines the curve that connects $\mathrm{P}_{1}$ to $\mathrm{P}_{2}$ and gives no control over $\beta$. Another parametrization that has been used in the past is a conical configuration [9]. For this case the number of independent geometrical parameters needed to define the afterbody end points are reduced to afterbody length $(L)$ and radial offset $\left(r_{i}-r_{9}\right)$. This parametrization usually includes a gradient discontinuity at the shoulder $\left(\mathrm{P}_{1}\right)$ and does not give any control over $\beta$. In this case the closing angle equals the afterbody mean angle $(\beta=\vartheta)$.

Much of the previously published information on afterbody design and aerodynamic performance is based on parametric experimental studies covering a range of radial offset and afterbody length [2], [4]. In typical wind-tunnel studies it is common practice to divide the model in forebody, centerbody and afterbody and the part instrumented for data acquisition is normally the external surface of the afterbody [10]. This enables measurements of the pressure distribution along the afterbody external contour for ranges of $M_{\infty}$ and NPR. The pressure readings are integrated to 
obtain pressure forces that are used to compute the pressure drag coefficient $C_{D 6}$ [2], [4], [9], [11]. There also have been previous computational studies on afterbody and nozzle system aerodynamic performance [12]-[14]. This data was mostly used to validate numerical schemes or as a case study and it was restricted to specific areas such as internal exhaust performance. Much of the previously published work about afterbody external aerodynamic performance employs simple convergent nozzle ducts or straight-walled convergent divergent ducts (Fig. 1). This affects the exhaust flow topology resulting in complex shock structures inside the nozzle duct and it changes the static pressure downstream of the nozzle exit section. This implies that the effect of the external afterbody geometry on afterbody aerodynamic performance is affected by the exhaust flow topology.

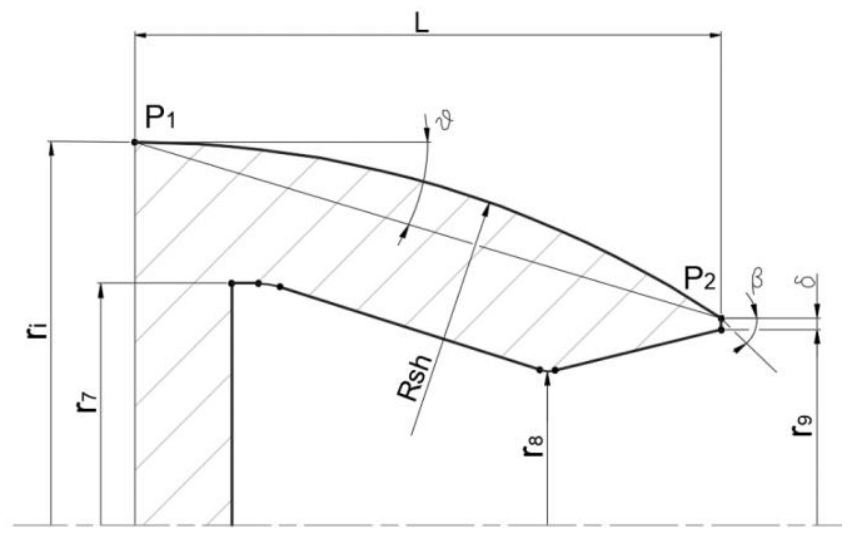

Fig. 1: Conventional afterbody geometry parametrized using a circular arc

\section{IV.Methodology}

\section{A. Afterbody and Exhaust Parametrization}

The axisymmetric afterbody parametrization is based on the CST method [7], [8]. This analytically defines geometries with desirable properties such as infinitely differentiable and continuous using an arbitrary number of intuitive Degrees of Freedom (DoF) [7] such as the location of the end points $\left(\mathrm{P}_{3}=\left[\mathrm{L}_{1}, \mathrm{r}_{\mathrm{i}}\right]\right.$ and $\left.\mathrm{P}_{2}=\left[\mathrm{L}, \mathrm{r}_{9}+\delta\right]\right)$, the slope at $\mathrm{P}_{3}$ and the slope at $\mathrm{P}_{2}$. In addition to the intuitive DoF some other constraints are set to improve the robustness of the geometry generation process. These are the second $\left(\left(d r^{2} / d^{2} x\right)_{P 3}\right)$ and third $\left(\left(d r^{3} / d^{3} x\right)_{P 3}\right)$ derivatives at $\mathrm{P}_{3}$ which are both set to 0 . This ensures that the shoulder of the afterbody does not overshoot and for $\mathrm{x}>\mathrm{x}\left(\mathrm{P}_{3}\right)$ it satisfies the condition $r(x)<r_{i}$ (Fig. 2). The total number of constraints needed to define one afterbody aeroline is 6 and this gives a curve of order 5 .

The internal exhaust duct is designed with the Method of Characteristics (MoC) [15], [16]. This provides the ideal nozzle contour for a given exit to throat area ratio $\left(\mathrm{A}_{9} / \mathrm{A}_{8}\right)$ that gives a smooth, shock-free, parallel flow at the nozzle exit section. This produces a cylindrical stream tube of constant section that minimizes the interaction terms between the exhaust internal flow and the afterbody external flow at the design NPR (DNPR) enabling the assessment of the effect of afterbody external geometry on the afterbody aerodynamic performance. The MoC implementation was based on a second order finite difference method and it assumes calorically perfect gas [17], [18]. The MoC-based exhaust duct uses one geometrical $\operatorname{DoF}\left(\mathrm{A}_{9} / \mathrm{A}_{8}\right)$ and takes the throat radius $\mathrm{r}_{8}$ (Fig. 3) as initial boundary condition. To assess the accuracy of the method the value of $\mathrm{A}_{9} / \mathrm{A}_{8}$ was converged within $0.005 \%$ of the input value. The convergent part of the nozzle duct has an inlet to throat area ratio equals to $\mathrm{A}_{7} / \mathrm{A}_{8}=2.25$ and was designed using a $3^{\text {rd }}$ order CST. This connects point $\mathrm{P}_{5}\left[\left(\mathrm{x}_{\mathrm{P} 6}-\mathrm{L} / 3\right), \mathrm{r}_{7}\right]$ to $\mathrm{P}_{6}\left(\mathrm{x}_{\mathrm{P} 6}, \mathrm{r}_{8}\right)$ (Fig. 3). Additional constraints on the convergent nozzle duct are the slope at $\mathrm{P}_{5}$ and the slope at $\mathrm{P}_{6}$, which are set to 0 . For CFD computational stability the point $\mathrm{P}_{5}$ is extended horizontally for a length equals to $0.03 \mathrm{~L}$ until intersection with the nozzle inlet. A complete afterbody and nozzle system geometry is then defined by 6 independent DoF: afterbody length $(\mathrm{L})$, shoulder radius $\left(\mathrm{r}_{\mathrm{i}}\right)$, nozzle base thickness $(\delta)$, boattail angle $(\beta)$, the straight shoulder length $\left(\mathrm{L}_{1}\right)$ and $\mathrm{A}_{9} / \mathrm{A}_{8}$ (Fig. 3). Given the geometric location of the end points $\mathrm{P}_{1}=\left[0, \mathrm{r}_{\mathrm{i}}\right]$ and $P_{2}=\left[L, r_{9}+\delta\right]$ and $A_{9} / A_{8}$, it is possible to specify different values of boattail closing angle $\beta$ and generate a family of different afterbody geometries. Relative to the circular arc afterbody the new parametrization offers an increased degree of flexibility (

Fig. 4 4). 


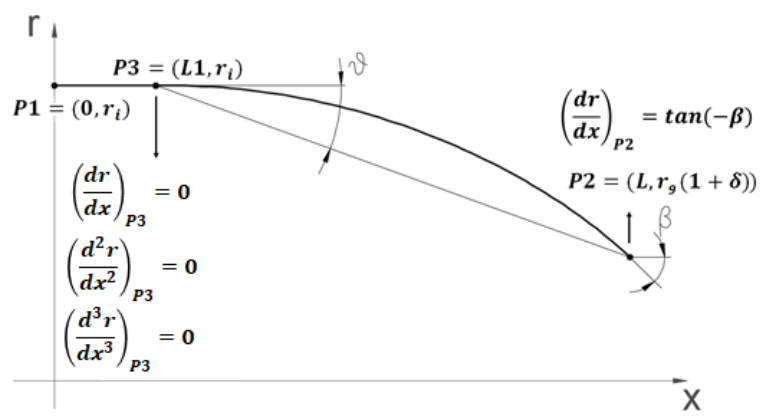

Fig. 2: Additional geometric constraint used to construct the afterbody geometry

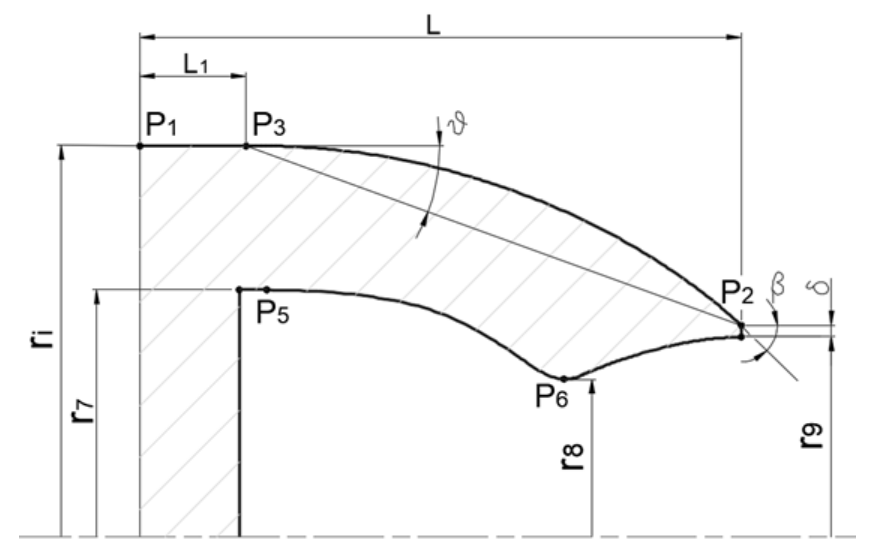

Fig. 3: Example of CST afterbody with ideal exhaust contour

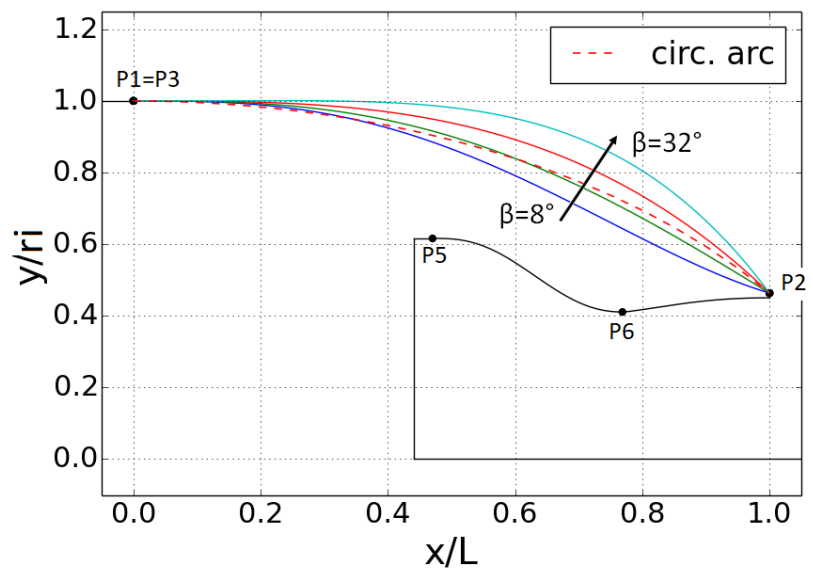

Fig. 4: Effect of $\beta$ on the afterbody geometry parametrized using the CST method

\section{B. CFD Analysis}

The afterbody aerodynamic data was generated using a steady CFD method. An implicit, density based, axisymmetric Favre Averaged Navier-Stokes (commonly referred as RANS) solver was used. The conservation equations were discretized with a second order scheme and the gradients were computed with a Green-Gauss nodebased method. The axisymmetric computational domain was a truncated circular far-field of radius $80 \mathrm{r}_{\mathrm{i}}$, a straight vertical inlet plane (Fig. 5), a symmetry axis (x-axis) and a sting that extends $22 r_{i}$ upstream of the afterbody from the point $P_{1}=\left(0, r_{i}\right)$. The sting was modelled as inviscid adiabatic wall for the initial portion close to the far-field boundary $\left(\mathrm{Ls}=6.6 \mathrm{r}_{\mathrm{i}}\right)$ and as a viscous adiabatic wall for the remaining part (Fig. 5a). All other walls were modelled as no-slip 
adiabatic boundary conditions. On the circular bounds and inlet plane of the domain a pressure far-field boundary condition was applied where the static pressure and temperature were prescribed. The free-stream Mach number was altered by changing the total pressure at the far-field with static pressure and static temperature kept constant. The inlet of the nozzle duct was modelled with a pressure inlet boundary condition where the NPR was changed by prescribing the inlet total pressure.

The computational mesh was generated using a hybrid approach with rectangular cells in the boundary layer and an unstructured mesh of triangular cells in the remaining part of the domain. The boundary layer was discretized with a set of 60 inflation layers spaced with a growth ratio of 1.15 and a target $y^{+}$of 1 . The appropriate mesh size was assessed through a grid independence study based on the Grid Convergence Index (GCI) approach. This uses a constant refinement ratio [19], [20] for the different meshes. The GCI was computed based on $C_{D}$ and three meshes of sizes 138, 444 and 1416 thousand elements. The GCI analysis was performed for two flight conditions: $M_{\infty}=0.8$ and $M_{\infty}=1.4$. The GCI index for the subsonic case was $0.4 \%$ between the coarse and medium mesh and $0.03 \%$ between the medium and the fine mesh based on $\mathrm{C}_{\mathrm{D}}$. For the supersonic case the GCI index was $0.8 \%$ between the coarse ad medium mesh and $0.02 \%$ between the medium and fine mesh. After this study, the medium mesh size of approximately 440 thousands elements was used.

The CFD approach was validated against experimental data [4] based on the performance of circular arc afterbodies. The afterbody pressure drag coefficient $\left(\mathrm{C}_{\mathrm{D} \beta}\right)$ was calculated for approximately 75 combinations of $M_{\infty}$ and power settings (NPR), ranging from $M_{\infty}=0.4$ to $M_{\infty}=1.3$ and NPR=1.4 to NPR=6.0. The CFD results generally correlate well with the experiments across the whole range for NPR, $M_{\infty}$ and for all the different afterbody geometries (Fig. 5b). A statistical analysis of the difference shows that about $86 \%$ of the results computed with the CFD approach are within a difference band of $\pm 0.01 \mathrm{C}_{\mathrm{D} \beta}$.

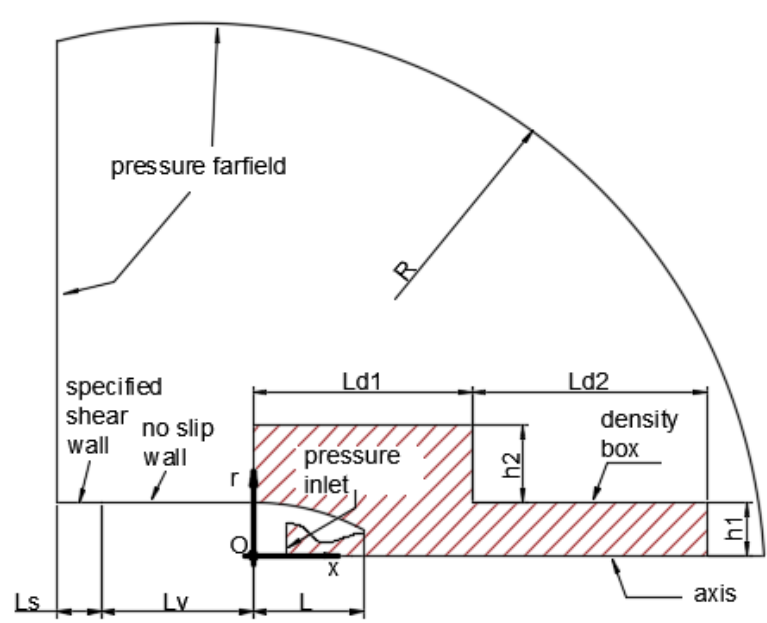

(a)

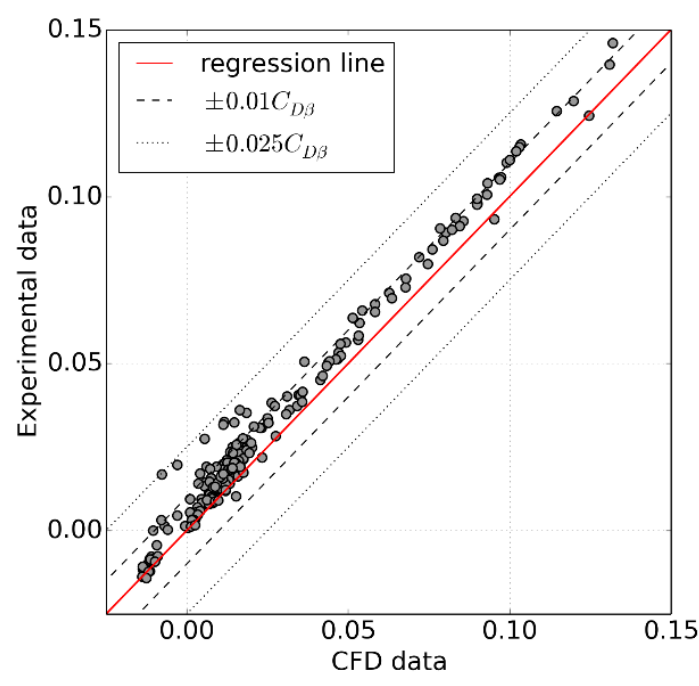

(b)

Fig. 5 (a) Computational domain and boundary conditions and (b) correlation between CFD and experimental $\mathrm{C}_{\mathrm{D} \beta}$ calculations

\section{Geometric and Aerodynamic Configurations}

To evaluate different aspects of axisymmetric afterbody and exhaust systems aerodynamic characteristics two Design Space Explorations (DSEs) are performed. These aim to quantify the effect of $A_{9} / A_{8}, \beta, \vartheta, \mathrm{NPR}$ and $M_{\infty}$ on afterbody drag, nozzle velocity coefficient and the overall balance of Net Afterbody Force (NAF). For the first study (DSE-1) three values of $A_{9} / A_{8}$ are chosen to study the effect of the operating conditions of variable area nozzles on afterbody drag (Fig. 6). A range of afterbody configurations are evaluated with $\beta$ of 10,20, 30 degrees (Fig. 7b) and $\vartheta$ across the range 7-20 degrees. The value of $\vartheta$ depends on the independent parameter $\mathrm{L}_{1}$ (Fig. 3) and $A_{9} / A_{8}$ (Fig. 7a). For all configurationss $\mathrm{L}, \delta$ and $A_{8}$ are kept constant. Based on previous work [11] $\delta$ was specified as $0.03 \mathrm{r}_{9}$. The total number of geometries was 36 generated using a full factorial approach of the ranges reported in Table 1a. The NPR varies independently in the interval 3.5 to 8.25 with a step size of approximately 0.75 and including the design point NPR of the three area ratios chosen. To capture the sensitivity of the afterbody drag to $M_{\infty}$ across the range 0.6-1.4 
the sample space was based on a Prandtl-Glauert factor $\left(\beta_{1}\right)$ spacing. For $M_{\infty}<1$ the $\beta_{1}$ step size is 0.08 while for $M_{\infty}>1$ the step size is 0.085 . The external Reynolds number per unit of length varied from $3.3 \times 10^{6}$ to $7.5 \times 10^{6}$ depending on $M_{\infty}$. All the cases are computed at $11 \mathrm{~km}$ of altitude in ISA ambient conditions and T7 is kept constant at $770 \mathrm{~K}$. The total number of aerodynamic conditions was 128 , spaced using a full factorial approach Table $1 \mathrm{~b}$. Overall the combined geometric and aerodynamic dataset comprised 4608 CFD simulations for DSE-1.

The aim of the second DSE (DSE-2) was to assess the aerodynamic performance of afterbody and nozzle systems when operated at design point NPR (DNPR). This includes the same ranges of aerodynamic DoF explored in DSE-1. These are 3.5 to 8.25 for NPR and 0.6-1.4 for $M_{\infty}$. The overall afterbody length $\mathrm{L}$ remains unchanged and so does the nozzle throat area $A_{8} . \beta$ varies in the interval 10-30 degrees with a step size of 10 degrees, $\vartheta$ varies in the range 7-20 and the values of $A_{9} / A_{8}$ are a function of NPR. In this DSE each value of $A_{9} / A_{8}$ corresponds to design point area ratio for the given value of NPR and T7. All the simulations take place at $11 \mathrm{~km}$ of altitude in ISA ambient conditions and $\mathrm{T} 7$ is kept constant at $770 \mathrm{~K}$. The number of aerodynamic conditions in DSE-2 is 128 (Table 2b) and the number of geometries is 12 (Table 2a), giving a total of 1536 cases spaced using a full factorial approach.

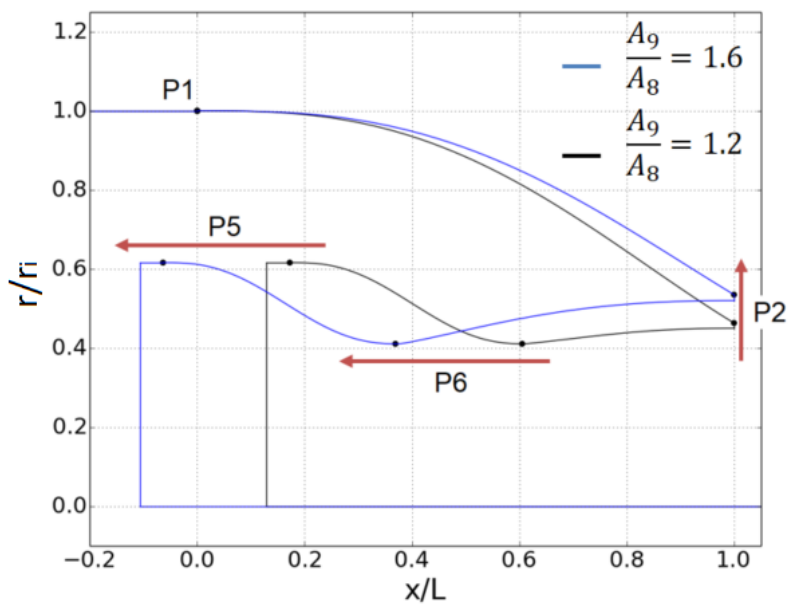

Fig. 6: Comparison of geometries for different values of $A_{9} / A_{8}$

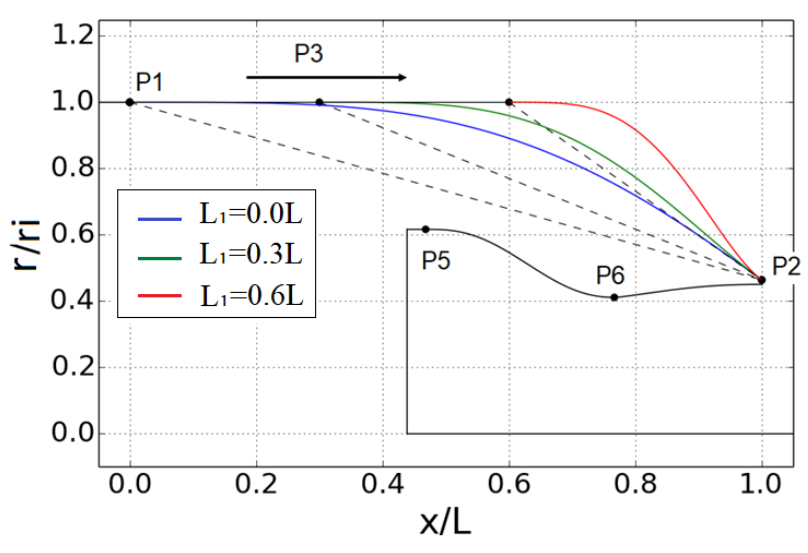

(a)

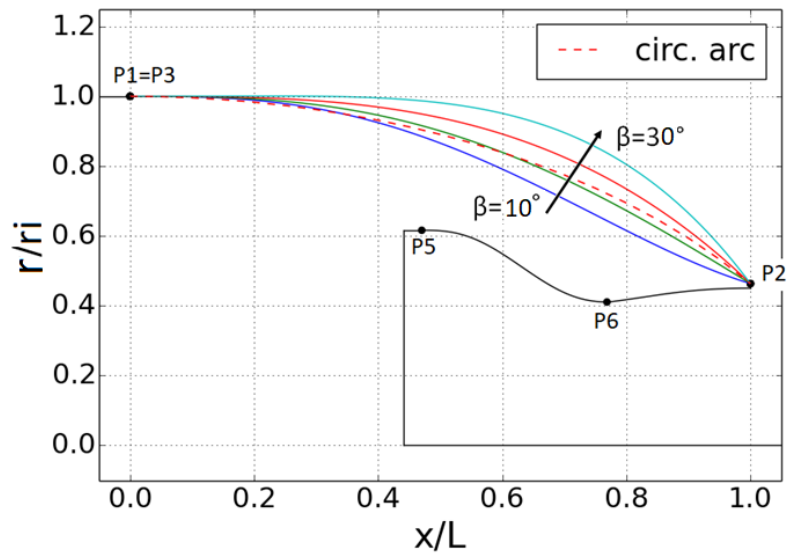

(b)

Fig. 7: Effect of (a) $\vartheta=\left[7^{\circ}-19^{\circ}\right]$ (b) $\beta=\left[10^{\circ}-30^{\circ}\right]$ for a geometry with $A 8=1.2$ 


\begin{tabular}{ccccc} 
DoF & Values & & & \\
\cline { 1 - 2 } $\mathrm{A}_{9} / \mathrm{A}_{8}$ & $1.2,1.4,1.6$ & DoF & Range \\
$\beta$ & $10^{\circ}, 20^{\circ}, 30^{\circ}$ & & $\mathrm{NPR}$ & $3.5-8.25$ \\
$\mathrm{~L}_{1}$ & $0.0 \mathrm{~L}, 0.2 \mathrm{~L}, 0.4 \mathrm{~L}, 0.6 \mathrm{~L}$ & & $M_{\infty}$ & $0.6-1.4$ \\
$(\vartheta)$ & $\left(\sim 5^{\circ}-20^{\circ}\right)$ Dependent variable & & &
\end{tabular}

(a)

(b)

Table 1 (a) Geometric DoF and (b) Aerodynamic DoF for DSE-1

\begin{tabular}{ccccc} 
DoF & Values & & \\
\cline { 1 - 1 } $\mathrm{A}_{9} / \mathrm{A}_{8}$ & function of NPR, range 1.16 to & & DoF & Range \\
$\beta$ & 1.782 & & $\mathrm{NPR}$ & $3.5-8.25$ \\
$\mathrm{~L}_{1}$ & $0.0 \mathrm{~L}, 0.2 \mathrm{~L}, 0.4 \mathrm{~L}, 0.6 \mathrm{~L}$ & & $M_{\infty}$ & $0.6-1.4$ \\
$(9)$ & $\left(\sim 5^{\circ}-20^{\circ}\right)$ Dependent variable & &
\end{tabular}

(a)

(b)

Table 2: (a) Geometric DoF and (b) Aerodynamic DoF for DSE-2

\section{Performance Metrics}

The performance metrics are based on the stream force and control volume approach [21] and is defined following the schematics and engine station numbers of Fig. 8. The performance of the exhaust system is assessed through the velocity coefficient $C_{V}(1)$, which is the ratio of the gross propulsive force at nozzle station $9\left(\mathrm{~F}_{9}\right)$ over the ideal propulsive force (IPF). IPF is the ideal gross propulsive force that the nozzle would generate if the exhaust flow was ideally expanded to ambient conditions.

$$
C_{V}=\frac{F_{9}}{I P F}=\frac{F_{7}-\vartheta_{n o z}}{I P F}
$$

Where $\mathrm{F}_{7}$ is the momentum and pressure force at nozzle station $7, \vartheta_{\text {noz }}$ is the pressure and shear force integrated along the internal nozzle walls from nozzle station 7 to station 9 (2).

$$
\vartheta_{n o z}=\int_{s t .7}^{s t .9} p d A \widehat{n}_{x}+\int_{s t .7}^{s t .9} \tau_{x} d A
$$

IPF is defined as (3):

$$
I P F=\dot{m}_{C F D} V_{9}^{i d e a l}
$$

Where $\dot{m}_{C F D}$ is the mass flow rate at station 7 while the ideal velocity at station $9\left(V_{9}^{\text {ideal }}\right)$ is calculated using ideal, zero-dimensional gas dynamics. For a choked convergent divergent nozzle $V_{9}^{\text {ideal }}$ is defined as: 


$$
V_{9}^{i d e a l}=\sqrt{\frac{2 \gamma R T_{7}}{\gamma-1}\left(1-\left(\frac{1}{N P R}\right)^{\frac{\gamma-1}{\gamma}}\right)}
$$

Where $\gamma$ is the specific heat ratio, $\mathrm{R}$ is the gas constant for dry air. The metric used to assess the aerodynamic performance of the afterbody is the drag coefficient $C_{D}$. This accounts for the effect of the viscous and pressure forces acting on the external afterbody surface including the nozzle base region (5).

$$
C_{D}=\frac{\phi_{a f t}}{\frac{1}{2} A_{1} V_{\infty}^{2} \rho_{\infty}}
$$

Where $\phi_{a f t}$ is the external drag force, $V_{\infty}$ is the free-stream velocity $\mathrm{A}_{\mathrm{i}}$ is the shoulder cross section area and $\rho_{\infty}$ is the free-stream density. The Net Afterbody Force (NAF) is defined as follows:

$$
N A F=F_{9}-\phi_{a f t}
$$

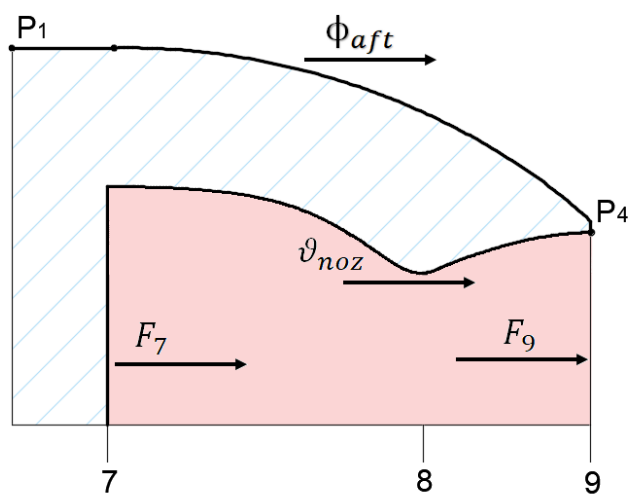

Fig. 8 Control volumes and forces definition for a generic afterbody and exhaust system

\section{V.Results and Discussion}

\section{A. Aerodynamic Characteristics}

\section{Internal exhaust performance}

The ideal internal nozzle contour is chosen to minimize the interaction effects between external afterbody surface and exhaust plume. This ensures that for a given a power setting (NPR, $\mathrm{A}_{9} / \mathrm{A}_{8}$ ) the nozzle performance remains unchanged regardless of $M_{\infty}$ and the external afterbody geometry. The nozzle performance metric $\mathrm{C}_{\mathrm{V}}$ is therefore well behaved and it only varies with NPR (Fig. 9) for the range of NPR and $A_{9} / A_{8}$ considered. To enable comparisons between $C_{D}$ and $C_{V}$ the forces ( $\phi_{a f t}$, NAF and $F_{9}$ ) are normalized with respect to $F_{9}$ at the DNPR for each specified $\mathrm{A}_{9} / \mathrm{A}_{8}$. This enables the understanding of the trade off between thrust and drag forces for different afterbody geometries and flight conditions $\left(M_{\infty}\right)$. 


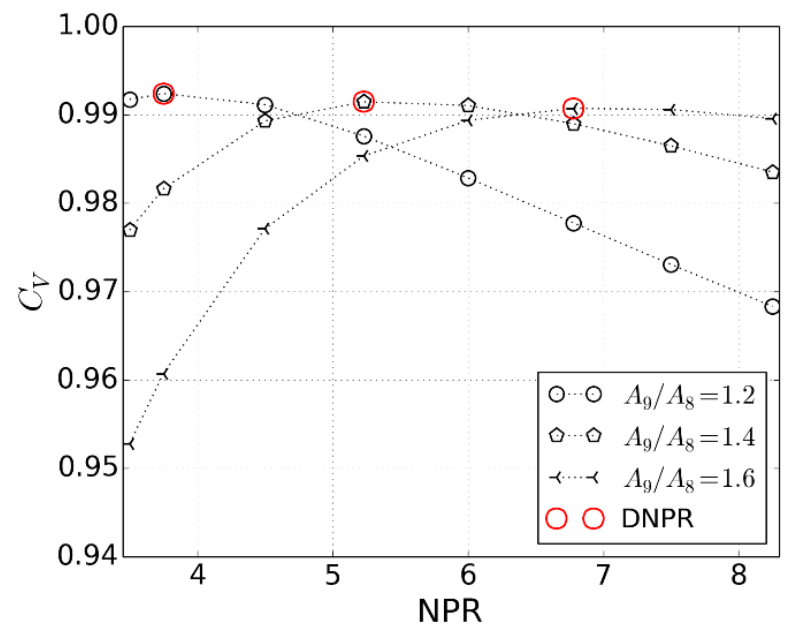

Fig. $9 \mathrm{C}_{\mathrm{V}}$ vs NPR for three values of $\mathrm{A}_{9} / \mathrm{As}_{8}, \beta=20^{\circ}, \mathrm{L} 1=0.0 \mathrm{~L}, M_{\infty}=1.0$

\section{External afterbody aerodynamic performance}

The primary metric of interest is $\mathrm{C}_{\mathrm{D}}$ which is dependent on the geometric $\left(\beta, \vartheta, A_{9} / A_{8}\right)$ and aerodynamic (NPR, $M_{\infty}$ ) parameters. As expected $M_{\infty}$ has a first order effect on $C_{D}$. Fig. 10 shows the effect of $M_{\infty}$ and $\beta$ and $\vartheta$ on $C_{D}$ for a geometry with a given value of $A_{9} / A_{8}$ operated at its design point NPR (DNPR). For low values of $\vartheta\left(7^{\circ}-8^{\circ}\right)$, corresponding to $\mathrm{L}_{1}=0.0 \mathrm{~L}$, the afterbody external flow is more sensitive to changes in $\beta$ due to the effect that this parameter has on the curvature distribution of the external contour line. When $\beta$ is low $\left(10^{\circ}\right)$ the rate of change of the geometric gradient between $\mathrm{P}_{1}=\left(0, \mathrm{r}_{\mathrm{i}}\right)$ and $\mathrm{P}_{2}=\left(\mathrm{L}, \mathrm{r}_{9}+\delta\right)$ (Fig. 3) is small which results in a smooth expansion of the external flow along the afterbody (Fig. 11a). As the value of $\beta$ increases and the afterbody closing shape gets steeper the external flow accelerates. This results in a lower static pressure distribution along the afterbody and an increase in $C_{D}$ (Fig. 11b). For larger values of $\vartheta\left(\sim 16^{\circ}-20^{\circ}\right)$ the shape of the afterbody between $\mathrm{P}_{3}=\left(\mathrm{L}_{1}, \mathrm{r}_{\mathrm{i}}\right)$ and $\mathrm{P}_{2}=\left(\mathrm{L}, \mathrm{r}_{9}+\delta\right)$ has a marginal impact on $C_{D}$. Even though the value of $\beta$ still controls the curvature distribution $\left(d r^{2} / d^{2} x\right)$ along the afterbody the rate of change of the geometrical gradient is greater to allow the CST line to reach $\mathrm{P}_{2}$ in a reduced length $\left(\mathrm{L}-\mathrm{L}_{1}\right)$. This causes the external flow to separate right after $\mathrm{P}_{3}$ (Fig. 12) making the afterbody drag insensitive to changes in $\beta$.

The off design operation of the exhaust impacts the flow topology downstream of nozzle station 9 and therefore it affects the shape of the post exit stream tube. The static pressure distribution along the afterbody at a given flight condition $\left(M_{\infty}\right)$ and for a given afterbody external geometry $(\beta, \vartheta)$ is affected by the shape of the post exit stream tube. For a fixed value of $\vartheta$, operating the nozzle in the under-expanded region always has a beneficial effect on $C_{D}$. For example, a geometry with $A_{9} / A_{8}=1.2, \beta=10^{\circ}$ and $\vartheta=10^{\circ}$ at $M_{\infty}=1.0$ has a $15 \%$ reduction in $C_{D}$ if NPR is increased from 3.75 (DNPR) to NPR=8.25 (Fig. 13). This happens because the oblique shock at nozzle station 9 gets stronger and consequently there is an increase in the static pressure of the exhaust plume (Fig. 14). As the static pressure in the exhaust plume increases, so does the static pressure on the external afterbody line and thereby it reduces $\mathrm{C}_{\mathrm{D}}$. For the over-expanded case the position of the shock on the external afterbody is not dependent on NPR. However, a geometry with $\mathrm{A}_{9} / \mathrm{A}_{8}=1.4$ (DNPR=5.23), $\beta=30^{\circ}$ and $\vartheta=14^{\circ}$ at $M_{\infty}=1.0$ has a $6 \%$ reduction in $\mathrm{C}_{\mathrm{D}}$ if NPR is decreased from 5.23 (DNPR) to NPR=3.5 (Fig. 15). The cross section of the stream tube reduces as NPR reduces affecting the shape of the separated region in the aft end of the external afterbody line. This changes the effective afterbody geometry and it affects the strength of the shock on the external afterbody shoulder. For example, for a geometry with $\mathrm{A}_{9} / \mathrm{A}_{8}=1.4$ (DNPR=5.23) (Fig. 15a), $\beta=30^{\circ}$ and $\vartheta=14^{\circ}$ at $M_{\infty}=1.0$ the pre-shock Mach number is 1.41 when the exhaust is operated at DNPR while it is 1.39 when the exhaust is operated at NPR=3.5 (Fig. 15b). This changes the flow expansion on the shoulder resulting in a lower static pressure distribution for the case with the higher pre-shock Mach number. In this case the afterbody drag reduces by $6 \%$. 


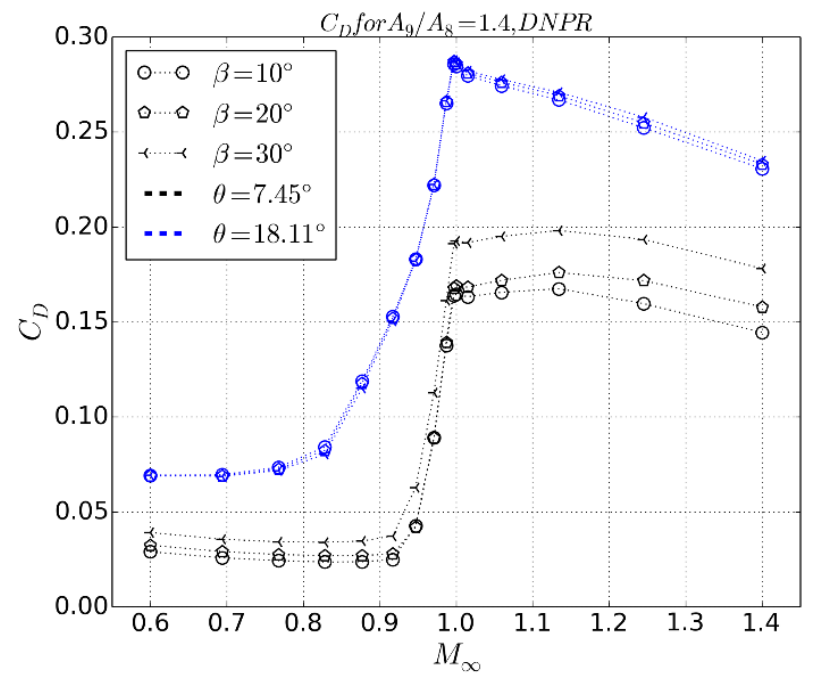

Fig. 10: $C_{D}$ lines for different values of $\beta$ and $\vartheta$

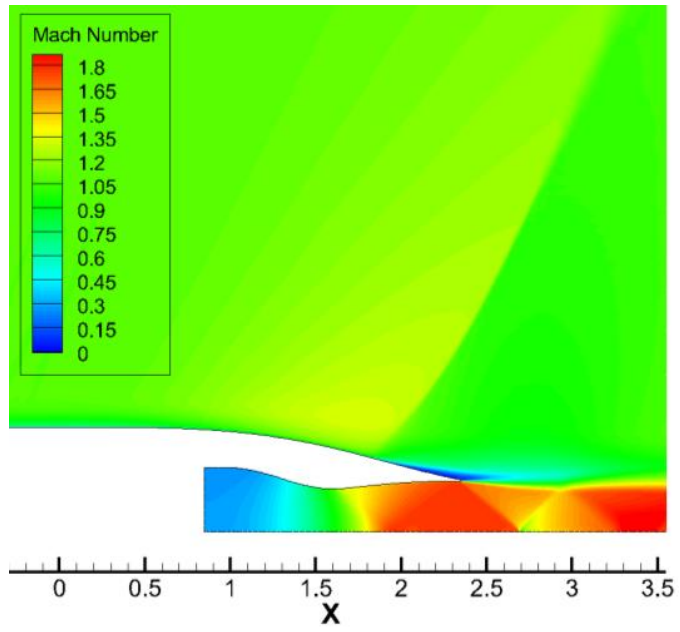

(a)

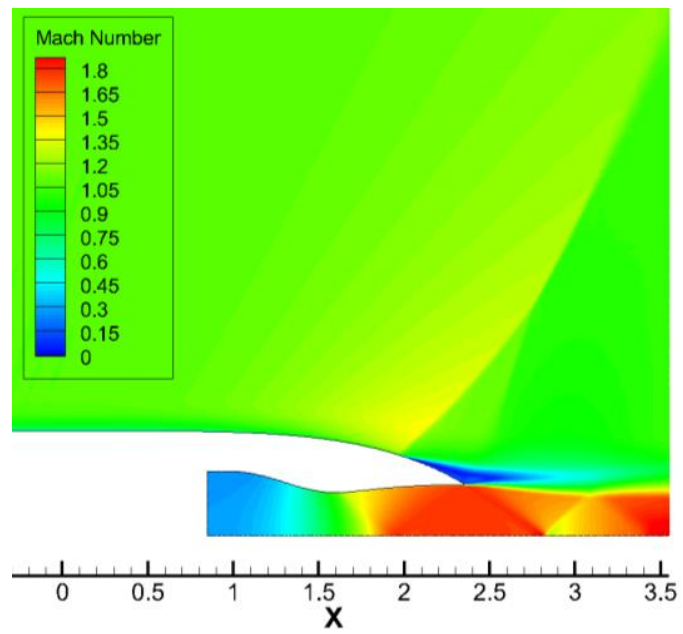

(b)

Fig. 11: Effect of $\beta$ for NPR=DNPR, $9=7.45^{\circ}, A 9 / A 8=1.4$ and $M_{\infty}=1.059-(a) \beta=10^{\circ}$ and $(b) \beta=30^{\circ}$

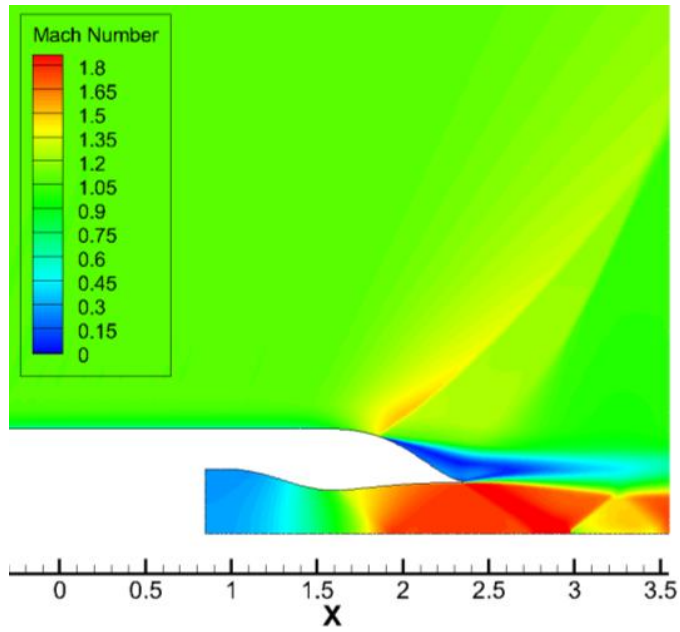

(a)

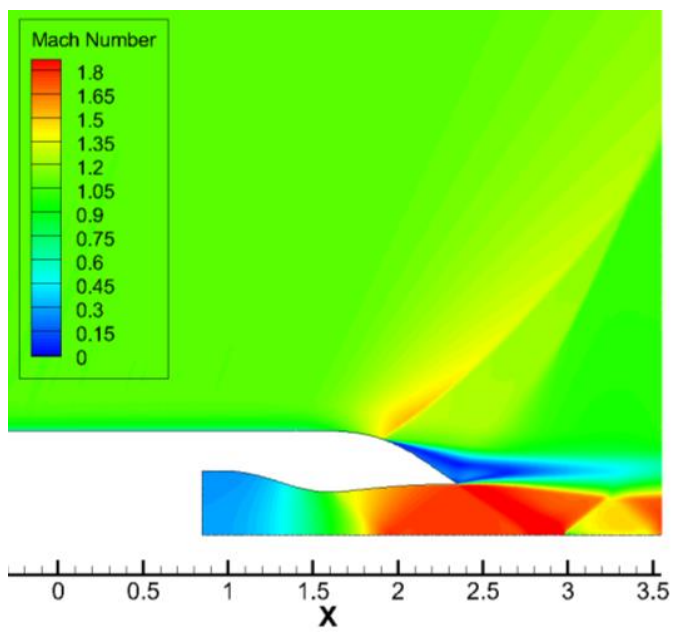

(b)

Fig. 12: Effect of $\beta$ for NPR=DNPR, $\vartheta=18.11^{\circ}, A 9 / A 8=1.4$ and $M_{\infty}=1.059-$ (a) $\beta=10^{\circ}$ and (b) $\beta=30^{\circ}$ 

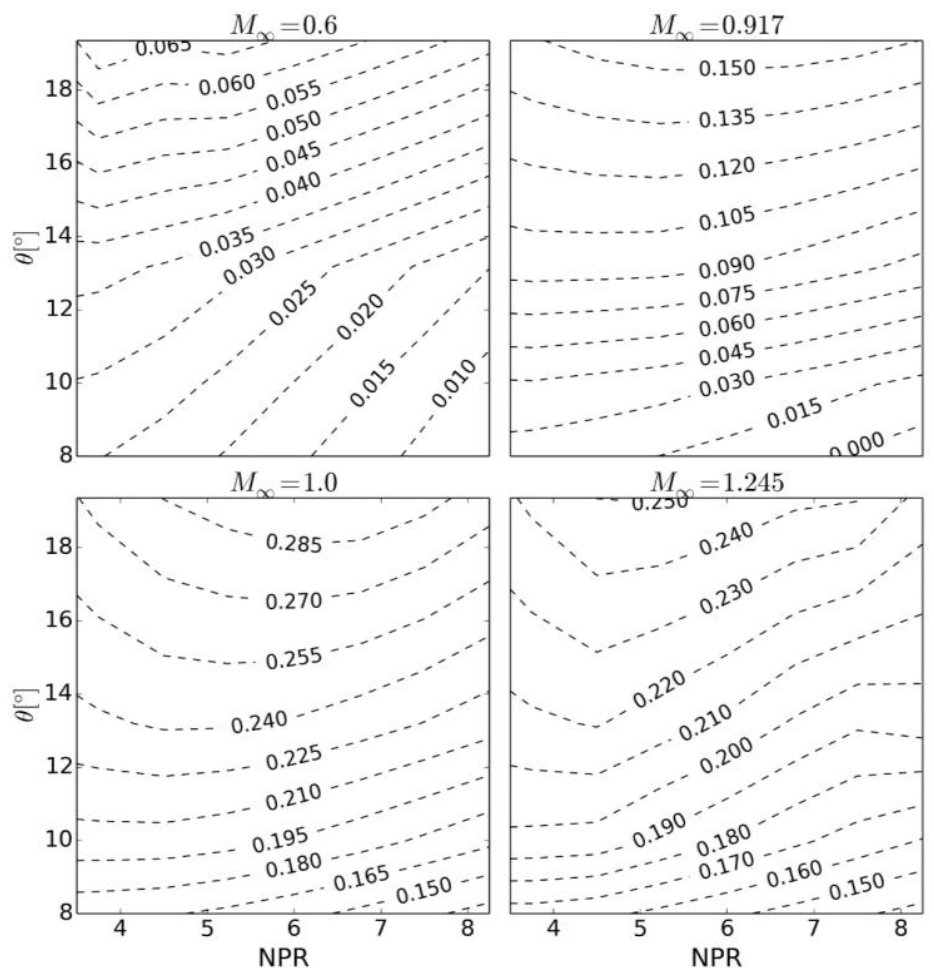

Fig. 13: $\mathrm{C}_{\mathrm{D}}$ iso lines $-\mathrm{A} 9 / \mathrm{A} 8=1.2 \beta=10^{\circ}$

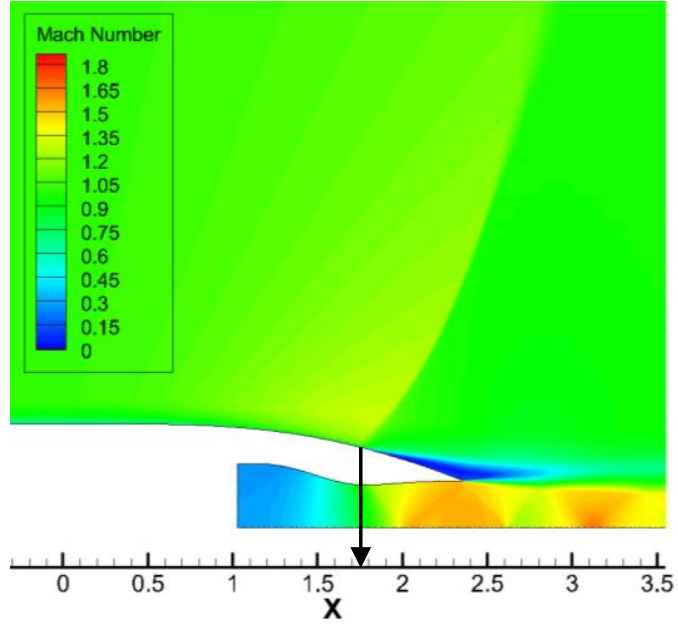

(a)

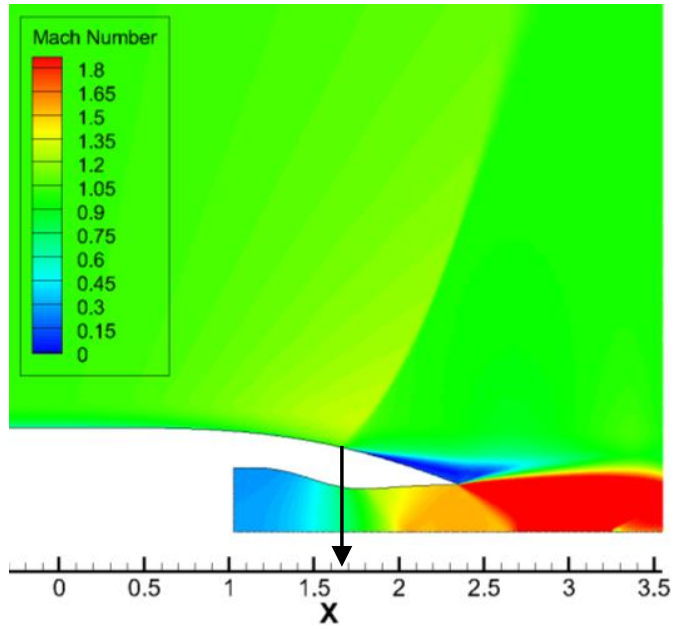

(b)

Fig. 14: Effect of NPR for $\beta=20^{\circ}, 9=8.0^{\circ}, A 9 / A 8=1.2$ and $M_{\infty}=0.997$ - (a) DNPR (b) NPR=8.25 

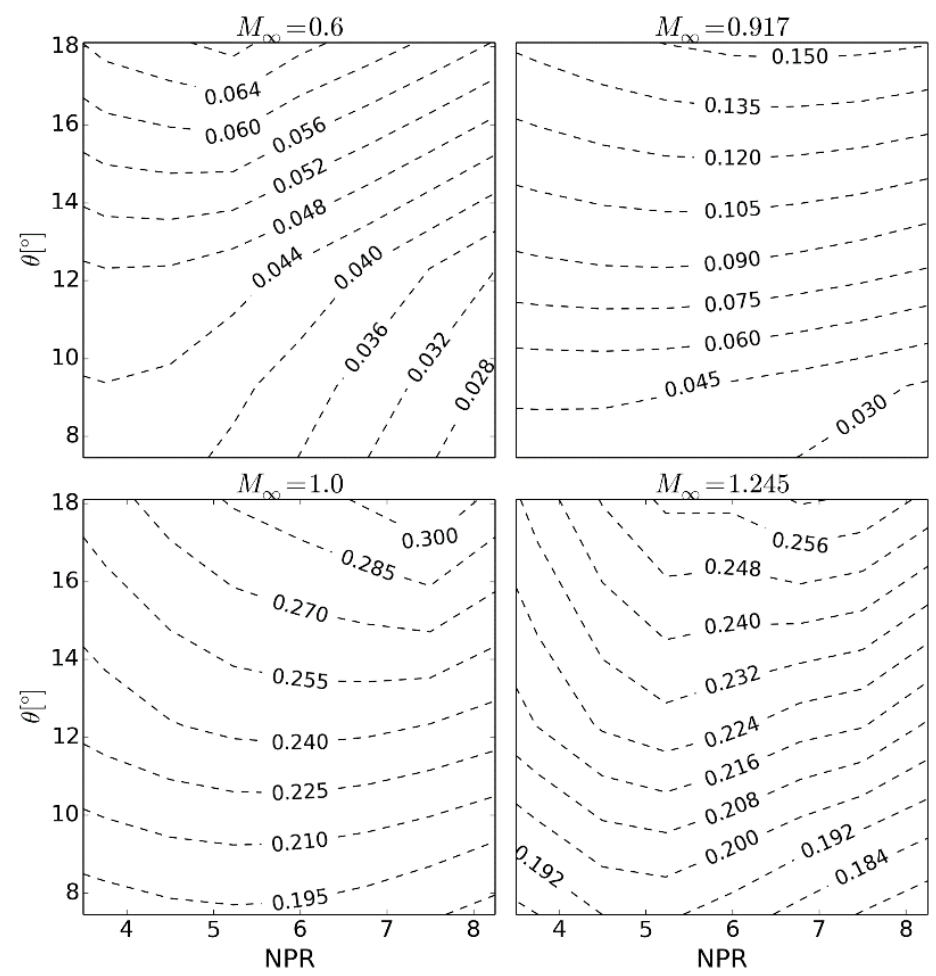

Fig. 15: $C_{D}$ iso lines $-A 9 / A s=1.4 \beta=30^{\circ}$

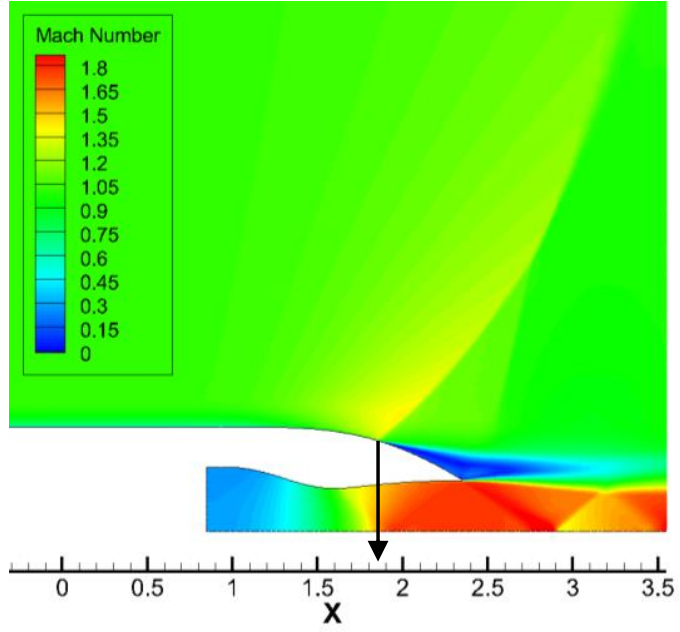

(a)

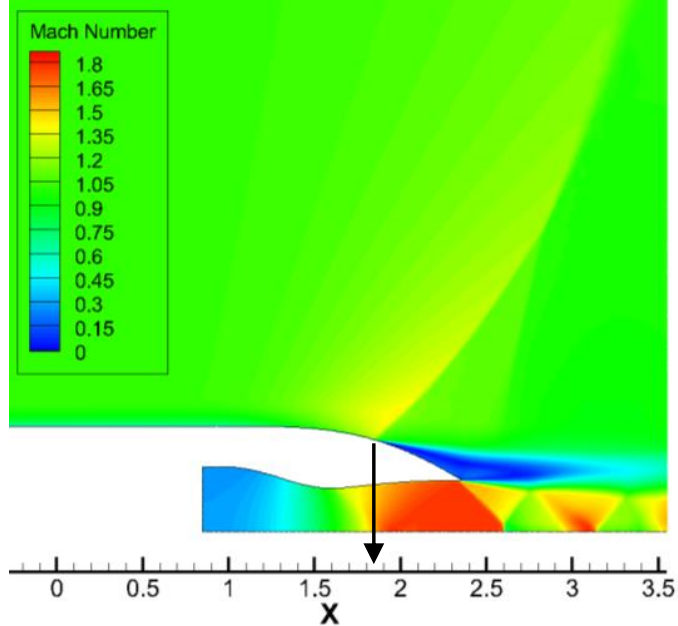

(b)

Fig. 16: Effect of NPR for $\beta=30^{\circ}, 9=12.3^{\circ}, A 9 / A 8=1.4$ and $M_{\infty}=1.0$ - (a) DNPR (b) NPR=3.5

\section{Overall afterbody and nozzle system performance}

Even though performance metrics such as $\mathrm{C}_{\mathrm{D}}$ are useful for preliminary design assessments, it does not consider the combined effect of afterbody and nozzle system designs. For instance, for a given geometry (Fig. 9, Fig. 13) as NPR increases both exhaust $C_{V}$ and afterbody drag $C_{D}$ are decreasing. In the context of preliminary design, it is useful to normalize all the forces $\left(\phi_{a f t}\right.$, NAF and $\left.\mathrm{F}_{9}\right)$ with the same value to understand the trade-off between the thrust domain and the drag domain. In the first instance drag and net afterbody force (NAF) are nondimensionalised with $\mathrm{F}_{9}$ at $\mathrm{DNPR}$ for a given value of $A_{9} / A_{8} . \mathrm{D}_{\mathrm{N}}$ and $\mathrm{NAF}_{\mathrm{N}}$ are defined as $\phi_{\text {aft }} / F_{9}(D N P R)$ and $N A F / F_{9}(D N P R)$ respectively. 
Fig. 17 shows the effect of $\beta$ and $\vartheta$ on the normalized drag $\left(D_{N}\right)$ force $\left(\phi_{a f t} / F_{9}(D N P R)\right)$ for a specified value of $A_{9} / A_{8}$ and $M_{\infty}$. For small values of $\vartheta$ the shape of the rear end of the afterbody has an effect on its aerodynamic performance. For $\vartheta=8.0^{\circ}, \mathrm{A} 9 / \mathrm{A} 8=1.2$ and $M_{\infty}=1.0$ an increase in $\beta$ from $10^{\circ}$ to $30^{\circ}$ accounts for approximately a $20 \%$ increase in $D_{\mathrm{N}}$ relatively to the geometry with $\beta=10^{\circ}$ operated at DNPR condition. For a given $\beta=20^{\circ}$ an increase in $\vartheta$ from $8^{\circ}$ to $19^{\circ}$ accounts for up to a $70 \%$ increase in $D_{N}$ The afterbody drag is less sensitive to NPR where for the more benign configuration of $\vartheta=8^{\circ} \mathrm{D}_{\mathrm{N}}$ reduces by about $23 \%$ when NPR increases from the DNPR of 3.75 to 8.25 . Conversely, for the more aggressive afterbody configurations with a relatively high mean angle $\left(\vartheta=19^{\circ}\right) \mathrm{D}_{\mathrm{N}}$ increases by up to $10 \%$ when NPR increases from the DNPR of 3.75 to a NPR of 6 . An increase in $\mathrm{A}_{9} / \mathrm{A}_{8}$, for a given value of $\mathrm{A}_{8}$, corresponds to an increase in $\mathrm{F}_{9}$ at DNPR and generally lower values of $\mathrm{D}_{\mathrm{N}}$ (Fig. 18, Fig. 19). However, the relative effect of each DoF remains broadly unchanged: for small values of $\vartheta$ the effect of an increase in $\beta$ results in approximately a $30 \%$ increase in $D_{N}$ while increasing NPR from 3.75 to 8.25 accounts for a $20 \%$ reduction in $D_{N}$. The largest effect is similarly due to a change in $\vartheta$. An increase in $\vartheta$ from $7^{\circ}$ to $17^{\circ}$ corresponds to up to an $80 \%$ increase in $\mathrm{D}_{\mathrm{N}}$.

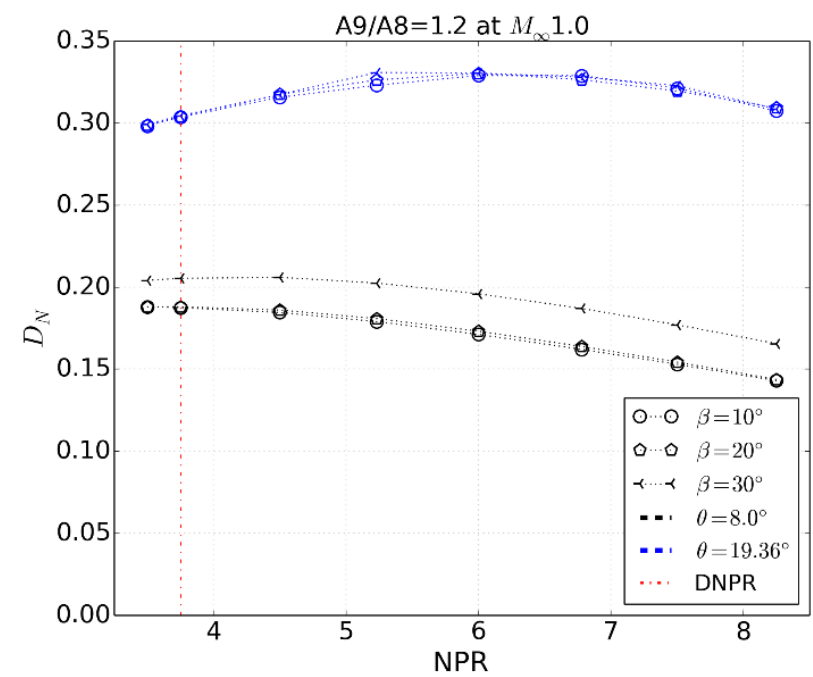

Fig. 17: effect of $\beta, 9$ and $N P R$ on $D_{N}$ for $A 9 / A s=1.2$ and $M_{\infty}=1.0$

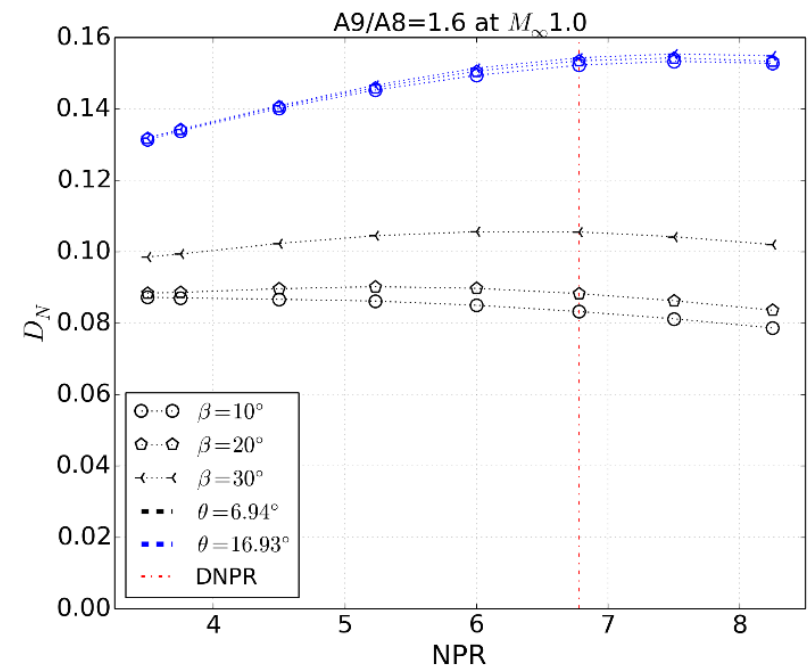

Fig. 18: effect of $\beta, \vartheta$ and NPR on $D_{N}$ for $A_{9} / A_{8}=1.6$ and $M_{\infty}=1.0$ 


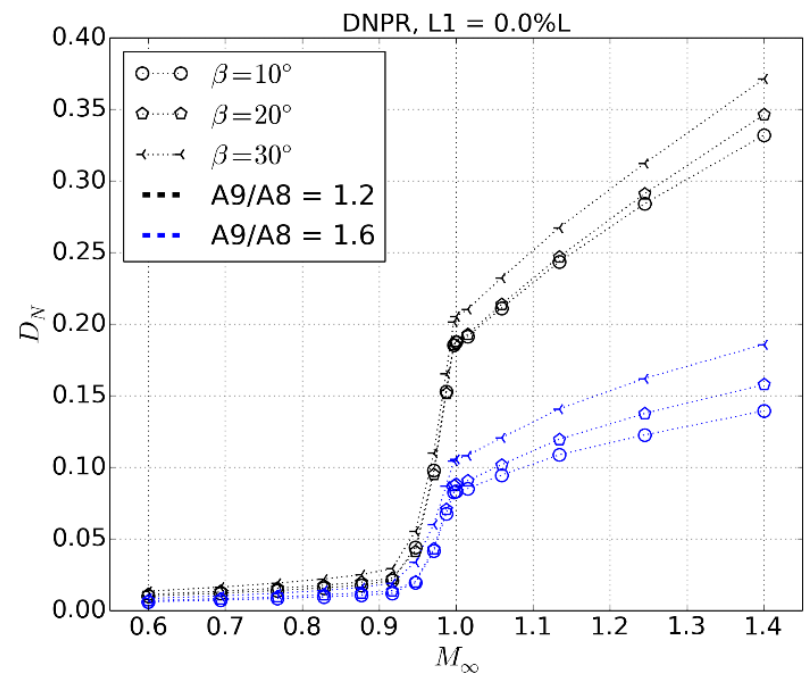

Fig. 19: effect of $\beta$ and $A_{9} / A_{8}$ on $D_{N}$ for $N P R=D N P R ~ \vartheta=8^{\circ}$ for $A_{9} / A_{8}=1.2$ and $\vartheta=7^{\circ}$ for $A_{9} / A_{8}=1.6$

The combined effect of the afterbody drag and exhaust thrust is evaluated using the normalized net afterbody force $\left(\mathrm{NAF}_{\mathrm{N}}\right)$, which is the NAF relative to $\mathrm{F}_{9}$ at $\mathrm{DNPR}\left(N A F / F_{9}(D N P R)\right)$. This quantifies how much the forward propelling force is relatively to the GPF at DNPR for a specified afterbody geometry and a specified throttle setting (NPR). For instance, for a geometry with $\mathrm{A}_{9} / \mathrm{A}_{8}=1.4, \beta=20^{\circ}$ operated at DNPR an increase in $\vartheta$ from $7.45^{\circ}$ to $18^{\circ}$ accounts for about a $12.5 \%$ reduction in $\mathrm{NAF}_{\mathrm{N}}$ at $M_{\infty}=1.4$ (Fig. 20a). On the other hand, for an afterbody and nozzle system with $\mathrm{A}_{9} / \mathrm{A}_{8}=1.4, \vartheta=7.45^{\circ}$ operated at its DNPR (5.23) an increase in $\beta$ from $10^{\circ}$ to $30^{\circ}$ can lead to a $7 \%$ reduction in $\mathrm{NAF}_{\mathrm{N}}$ at $M_{\infty}=1.4$ (Fig. 20b). For larger $\mathrm{A}_{9} / \mathrm{A}_{8}$ the $\mathrm{NAF}_{\mathrm{N}}$ values are progressively smaller as $M_{\infty}$ due to the increase in $\mathrm{F}_{9}(\mathrm{DNPR})$ (Fig. 21b, c) while the opposite happens for smaller $\mathrm{A}_{9} / \mathrm{A}_{8}$ (Fig. 21a).

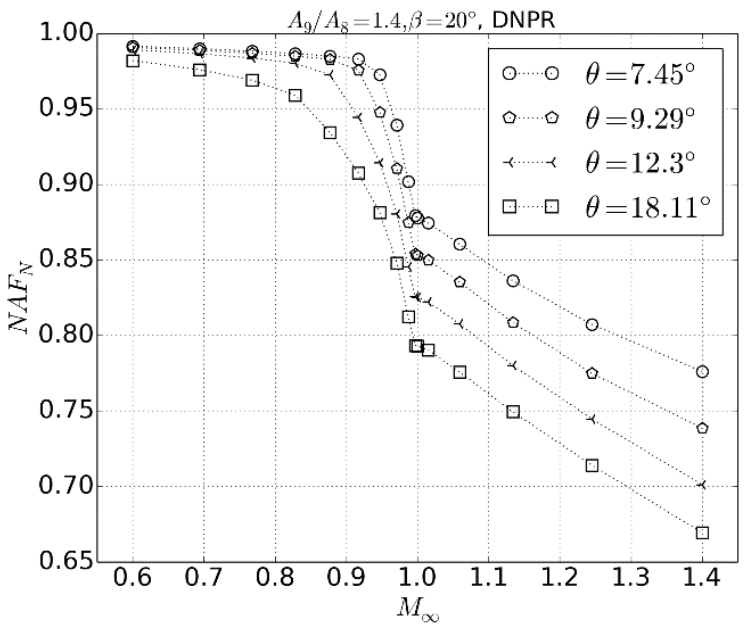

(a)

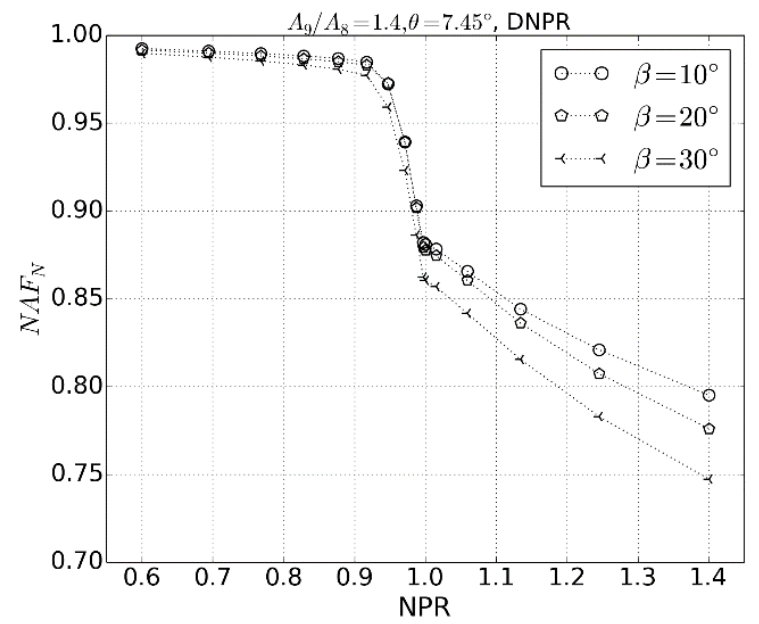

(b)

Fig. 20: (a)effect of $\vartheta$ and (b) effect of $\beta$ on $N A F_{N}$ for $A 9 / A_{8}=1.4$ at $D N P R$ 


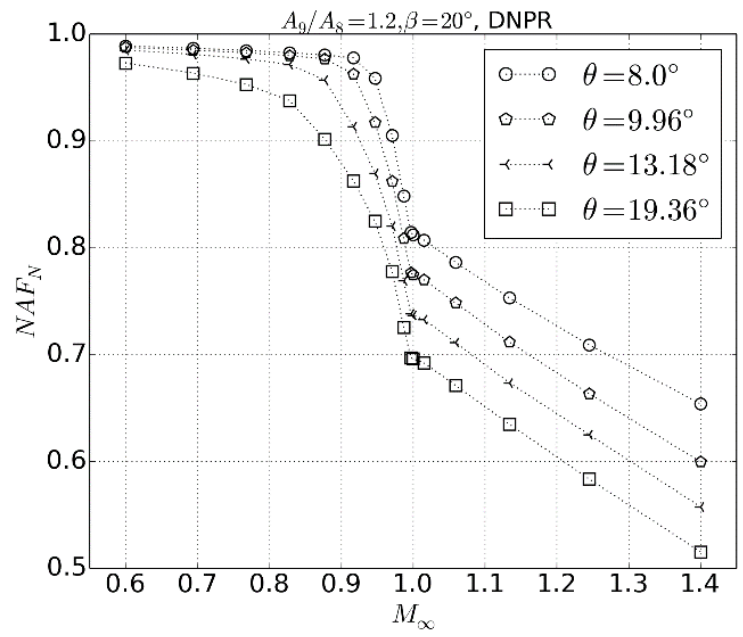

(a)

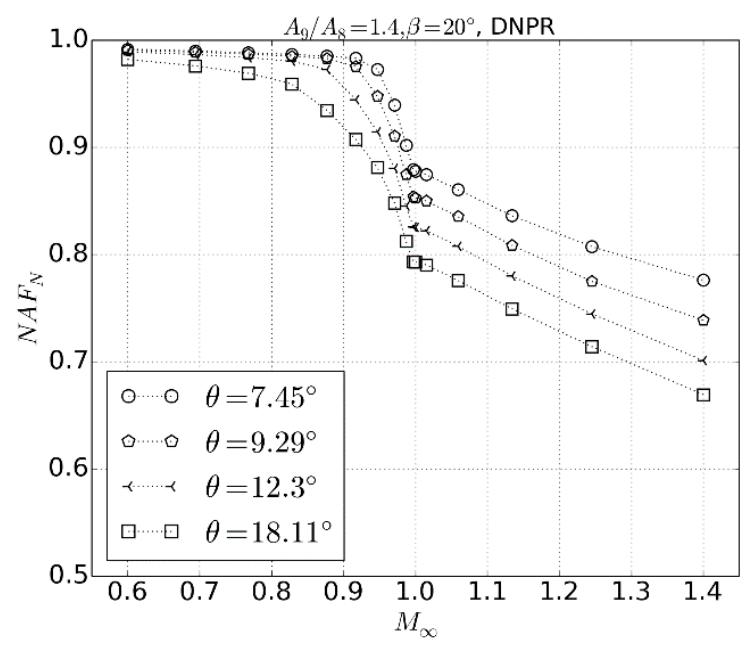

(b)

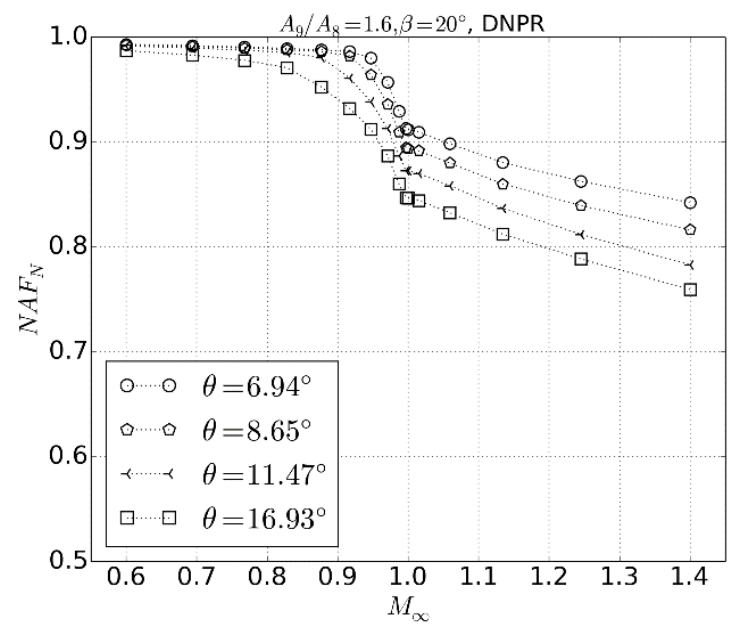

(c)

Fig. 21: Effect of 9 on $\mathrm{NAF}_{\mathrm{N}}$ for (a) $\mathrm{A} 9 / \mathrm{A}_{8}=1.2$, (b) $\mathrm{A} 9 / \mathrm{A}_{8}=1.4$ and (c) $\mathrm{A} 9 / \mathrm{A}_{8}=1.6$ at $\mathrm{DNPR}$

For preliminary design purposes it is important to understand how all the forces acting on an afterbody and nozzle system compare with the maximum thrust achievable for a given geometry at a given operating condition. For this purpose $\mathrm{NAF}_{\mathrm{R}}$ is defined as $N A F_{R}=N A F /\left(F_{9 \max }(N P R)\right) . \mathrm{F}_{9 \max }(\mathrm{NPR})$ is defined as the $\mathrm{F}_{9}$ produced by a geometry that has a given NPR as DNPR. This is the maximum $\mathrm{F}_{9}$ achievable with an ideal exhaust contour at a certain NPR. This quantifies how much of the maximum achievable forward propelling force for a given NPR is lost due to the combination of afterbody and exhaust geometry and $M_{\infty}$. Since for the idealized exhaust contour $\mathrm{C}_{\mathrm{V}}$ at DNPR is not dependent on any of the geometry or on $M_{\infty}$ this normalization can be used across the DSE results. This combines the data obtained from DSE- 1 and DSE-2. For a geometry with $A_{9} / A_{8}=1.6$ and $9=6.94^{\circ}$ an increase in $\beta$ from $10^{\circ}$ to $30^{\circ}$ reduces $\mathrm{NAF}_{\mathrm{R}}$ by up to $15 \%$ across the range of NPR from 3.5 to 8.25 . For the same geometry $\left(A_{9} / A_{8}=1.6\right.$ and $\left.\vartheta=6.94^{\circ}\right)$ at a given value of $\beta=20^{\circ}$ when NPR is decreased from 8.25 to 3.5 there is a $35 \%$ reduction in $\mathrm{NAF}_{\mathrm{R}}$ relative to the maximum NPR value at $M_{\infty} .=1.4$ (Fig. 22a). The effect of an increase in $\vartheta$ from $6.94^{\circ}$ to $16.93^{\circ}$ is up to a $31 \%$ reduction in $\mathrm{NAF}_{R}$ (Fig. 22b). The effect of different values of $\mathrm{A}_{9} / \mathrm{A}_{8}$ on $\mathrm{NAF}_{\mathrm{R}}$ is relatively small for geometries with small $\vartheta$ ( or $\mathrm{L}_{1}$ ). In the case of a geometry with $\beta=10^{\circ}$ the effect of increasing $\mathrm{A}_{9} / \mathrm{A}_{8}$ from 1.2 to 1.6 is relevant only for large values of NPR and it accounts for a $5 \%$ increase in $\mathrm{NAF}_{\mathrm{R}}$ relatively to $A_{9} / A_{8}=1.2$ (Fig. 23a). For a geometry with $\beta=30^{\circ}$ the effect of an increase in the value of $A_{9} / A_{8}$ is relevant only for low values of NPR and it accounts for an $8 \%$ increase in $\mathrm{NAF}_{\mathrm{R}}$ relatively to $\mathrm{A}_{9} / \mathrm{A}_{8}=1.6$ (Fig. 23b). For 
geometries with larger $\vartheta \mathrm{NAF}_{\mathrm{R}}$ is insensitive to changes in $\mathrm{A}_{9} / \mathrm{A}_{8}$ and $\beta$ (Fig. 24a). For lower $M_{\infty}$ the $\mathrm{NAF}_{\mathrm{R}}$ curves move to higher values (Fig. 24b).

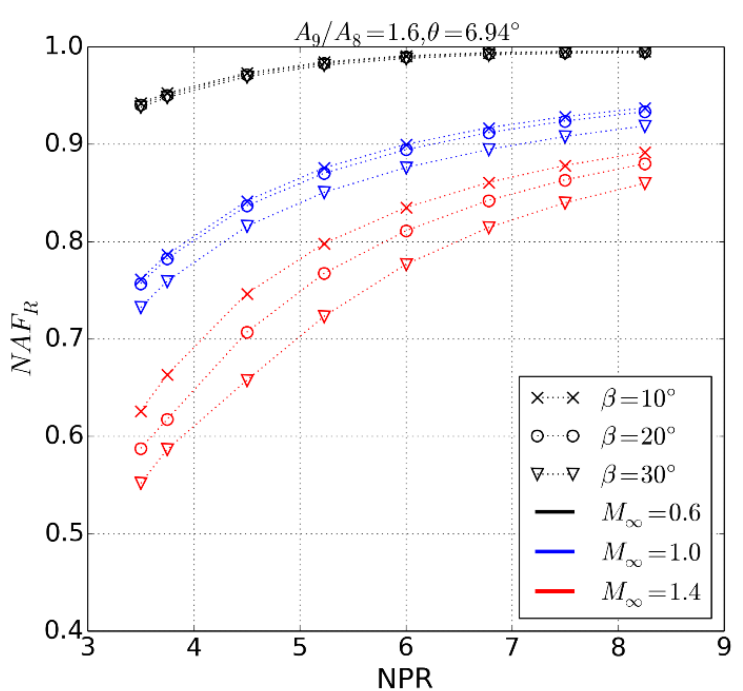

(a)

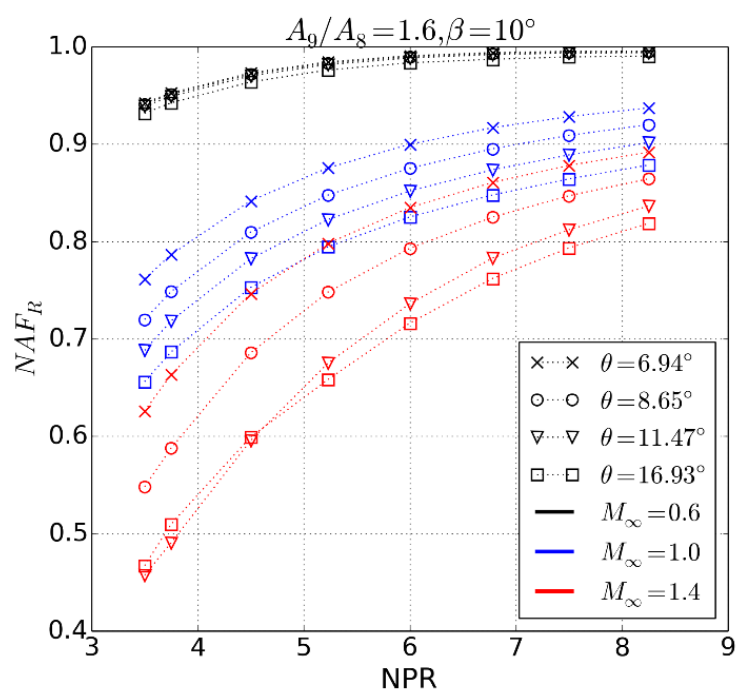

(b)

Fig. 22: (a)effect of NPR, $\beta, M_{\infty}$ on $N A F_{R}, \vartheta=6.94^{\circ}$ and (b) effect of $9, N P R, M_{\infty}$ on $N_{A F}, \beta=10^{\circ}$

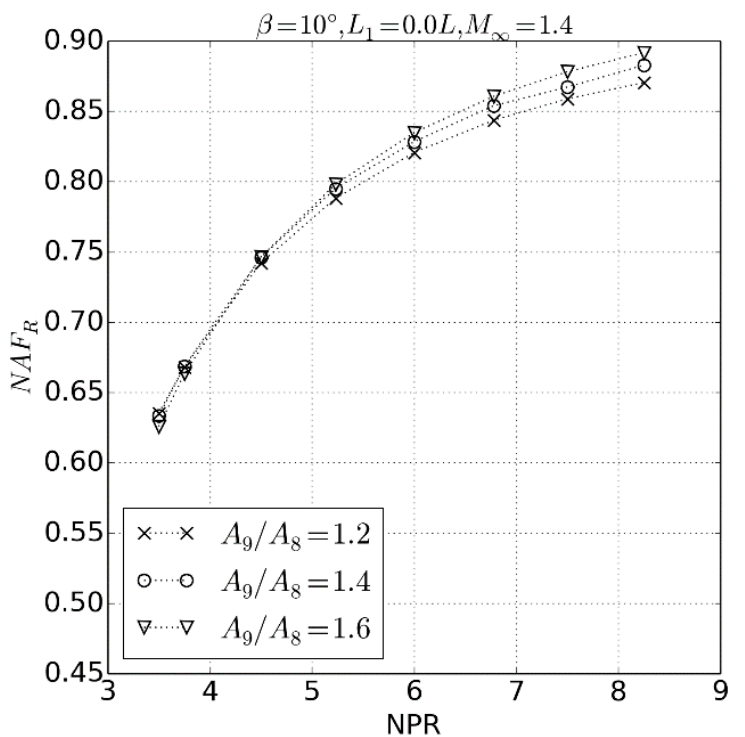

(a)

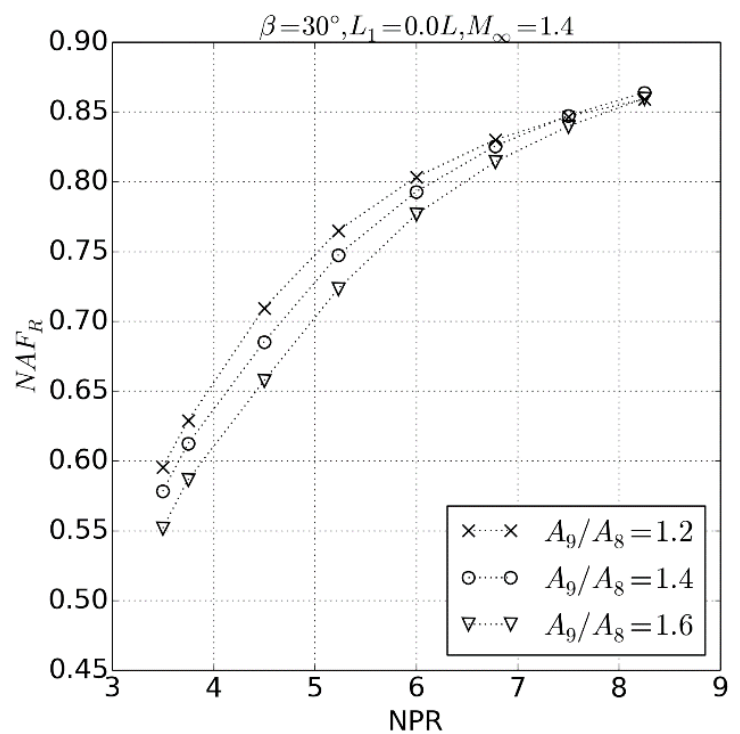

(b)

Fig. 23: effect of $A_{9} / A_{8}$ and NPR on $N_{A F}$ for (a) $\beta=10^{\circ}$ and (b) $\beta=30^{\circ}$ 


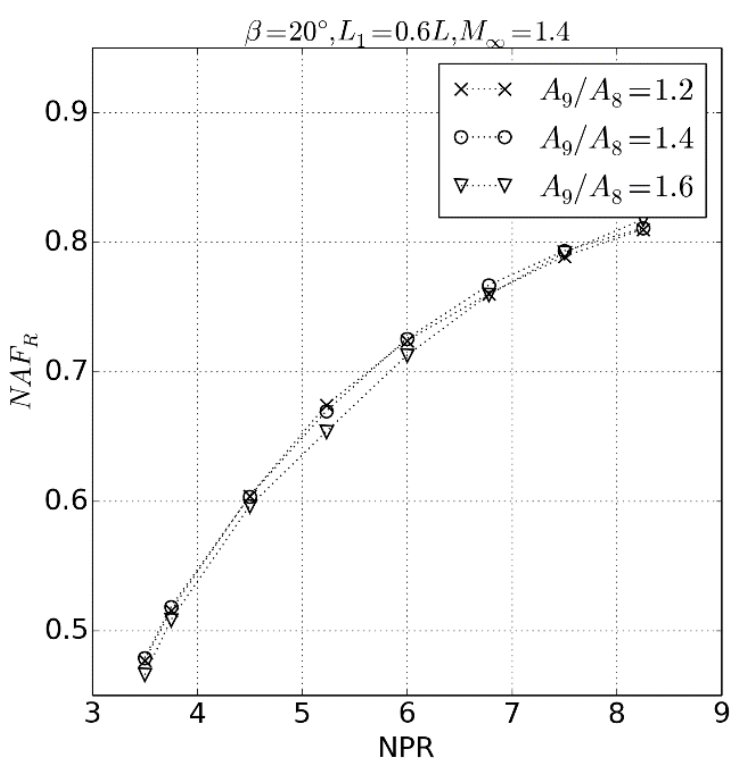

(a)

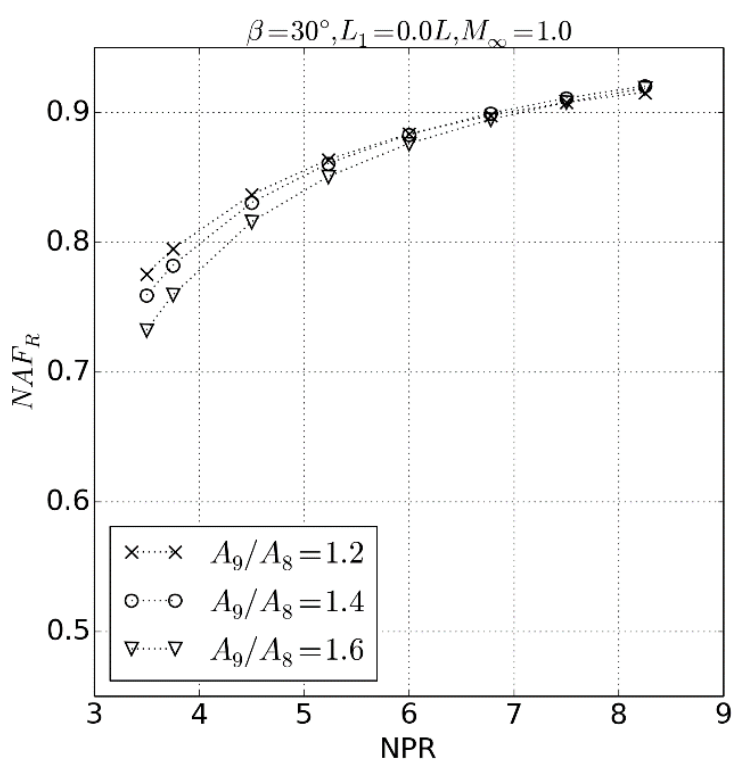

(b)

Fig. 24: effect of $A_{9} / A_{8}$ and NPR on $\mathrm{NAF}_{\mathrm{R}}$ for $(\mathrm{a}) \beta=20^{\circ}, \mathrm{L}_{1}=0.6 \mathrm{~L} M_{\infty}=1.4$ and (b) $\beta=30^{\circ}, \mathrm{L}_{1}=0.0 \mathrm{~L} M_{\infty}=1.0$

\section{VI.Conclusions}

This research has quantitatively assessed the impact of axisymmetric afterbody geometry and nozzle system aerodynamic performance under a range of flight conditions $\left(M_{\infty}\right)$ and throttle settings (NPR). The key factor that enabled this work to develop was a novel external afterbody geometry parametrization based on the CST method. This proved more flexible than the conventional parametrizations and allowed the exploration of three main geometric DoF: afterbody mean angle ( $\vartheta$, boattail closing angle $(\beta)$ and nozzle exit to throat area ratio $\left(A_{9} / A_{8}\right)$. Based on this work it can be concluded that:

- $\vartheta$ has a relevant impact on $C_{D}$. An increase in the value of $\vartheta$ from $7^{\circ}$ to $20^{\circ}$ can increase $C_{D}$ by $80 \%$. $\vartheta$ has a large impact on both $\mathrm{NAF}_{\mathrm{N}}$ and $\mathrm{NAF}_{\mathrm{R}}$. An increase in $\vartheta$ can reduce $\mathrm{NAF}_{\mathrm{N}}$ by $12.5 \%$ and $\mathrm{NAF}_{\mathrm{R}}$ by approximately $30 \%$.

- $\quad \beta$ has an impact on the afterbody drag only when the external flow undergoes a smooth expansion around the external afterbody shoulder. This happens for small values of $\vartheta$. An increase in $\beta$ from $10^{\circ}$ to $30^{\circ}$ can cause up to a $25 \%$ increase in $\mathrm{C}_{\mathrm{D}}$ and up to a $8 \%$ decrease in $\mathrm{NAF}_{\mathrm{N}}$. The decrease in $\mathrm{NAF}_{\mathrm{R}}$ due to an increase in $\beta$ can be up to $15 \%$.

- NPR affects the shape of the exhaust stream tube. This affects the position of the shock on the afterbody external surface as well as the shape of the separated region close to its aft end. Both over-expanded and under-expanded operating conditions result in up to a $15 \%$ reduction in $\mathrm{C}_{\mathrm{D}}$. Increasing NPR from 3.5 to 8.25 is beneficial for $\mathrm{NAF}_{\mathrm{R}}$ especially at supersonic $M_{\infty}$ where the $\mathrm{NAF}_{\mathrm{R}}$ improvement can be up to $50 \%$.

\section{References}

[1] D. Cler, "A parametric investigation of nozzle planform and internal /external geometry at transonic speeds," in 31st Joint Propulsion Conference and Exhibit, 1995.

[2] D. E. Reubush and J. F. Runckel, "Effect of Fineness Ratio on Boattail Drag of Circular-Arc Afterbodies Having Closure Ratio of 0.50 With Jet Exhaust at Mach Numbers up to 1.30," NASA TN D-7192, Hampton, Virginia, 1973.

[3] P. R. Payne, R. M. Hartley, and R. M. Taylor, "Afterbody Drag: Volume 1 - Drag of Conical and Circular Arc Afterbodies without Jet Flow," Bethesda, Maryland, 1980.

[4] D. E. Reubush, "Effect of Fineness and Closure Ratios on Boattail Drag of Circular-Arc Afterbody Models With Jet Exhaust at Mach Numbers up to 1.30," NASA TN D-7163, Hampton, Virginia, 1973.

[5] G. Carson and E. E. Lee, "Experimental and Analytical Investigation of Axysimmetric Supersonic Cruise 
Nozzle Geometry at Mach Numbers From 0.60 to 1.30,” NASA TP-1953, Hampton, Virginia, 1981.

[6] G. S. Pick and R. M. Hartley, “Afterbody Drag Volume 3 - Literature Survey,” Bethesda, Maryland, 1980.

[7] R. Christie, A. Heidebrecht, and D. MacManus, "An Automated Approach to Nacelle Parameterization Using Intuitive Class Shape Transformation Curves," J. Eng. Gas Turbines Power, vol. 139, no. 6, 2017.

[8] B. M. Kulfan, “CST' Universal Parametric Geometry Representation Method With Applications to Supersonic Aircraft,” J. Aircr., vol. 45, no. 1, 2008.

[9] Royal Aeronautical Society, "Subsonic pressure drag of boat-tails with negligible annular base area in the presence of a central propulsive jet," ESDU 01012, 2001.

[10] Langley Research Center, "NASA TM-102750 - A User's Guide to the Langley 16-Foot Transonic Tunnel Complex," Hampton, Virginia, 1990.

[11] L. E. Putnam and C. E. Mercer, "Pitot-Pressure Measurements in Flow Field Behind a Rectangular Nozzle With Exhaust Jet for Free-Stream Mach Numbers of 0.00, 0.60, and 1.20," NASA TM-88990, Hampton, Virginia, 1986.

[12] H. Chen, U. Navier, S. Computation, Y. Zhang, and H. Chen, "Performance Prediction of Conical Nozzle using Navier-Stokes Computation Performance Prediction of Conical Nozzle," J. Propuls. Power, vol. 31 , no. 1, pp. 192-203, 2015.

[13] J. R. Debonis, N. J. Georgiadis, and C. F. Smith, "Validation of the NPARC Code for Nozzle Afterbody Flows at Transonic Speeds," NASA TM 106971, 1995.

[14] R. G. M. Hasan, J. J. McGuirk, D. D. Apsley, and M. A. Leschziner, “A turbulence model study of separated 3D jet/afterbody flow," Aeronaut. J., vol. 108, no. 1079, 2004.

[15] J. D. Anderson, Modern Compressible Flow With Historical Perspective, Second Ed. McGraw-Hill, 1990.

[16] A. H. Shapiro, The Dynamics and Thermodynamics of Compressible Fluid Flow. New York: The Ronald Press Company, 1954.

[17] T. Zebbiche, "Supersonic axisymmetric minimum length nozzle conception at high temperature with application for air," KSAS Int. J., vol. 9, no. 1, pp. 1-30, 2008.

[18] B. M. Agrow and G. Emanuel, "Comparison of minimum length nozzles - Agrow, B. M..pdf," J. Fluids Eng., vol. 110, pp. 283-288, 1988.

[19] P. J. Roache, "Perspective: A Method for Uniform Reporting of Grid Refinement Studies," J. Fluids Eng., vol. 116, pp. 405-413, 1994.

[20] F. Elizalde-Blancas and P. J. Roache, "An Evaluation of the GCI for Unstructured Grids."

[21] AGARD 237, "Guide to In-Flight Thrust Measurement of Turbojets and Fan Engines," 1979. 
2020-01-05

\section{Geometry parametrization and aerodynamic characteristics of axisymmetric afterbodies}

\section{Zuccolo, Giovanni}

\section{AIAA}

Zuccolo G, MacManus D, Goulos I, Martin P (2020) Geometry parametrization and aerodynamic characteristics of axisymmetric afterbodies. In: 2020 AIAA SciTech Forum, 6-10 January 2020

Orlando, Florida

https://doi.org/10.2514/6.2020-2222

Downloaded from Cranfield Library Services E-Repository 